\title{
THE EFFECT OF ANIMATED PLAY PROGRAM ON IRREGULAR POSTURE FORMATION IN PRESCHOOL CHILDREN
}

\author{
Laura Daniusevičiūtè-Brazaitė, Brigita Grèbliauskienė \\ Kaunas University of Technology, Kaunas, Lithuania
}

\begin{abstract}
Background. Insufficient back muscle tone of 6-7-year-old children does not guarantee stable spin curves. The preschool children's posture is an important society problem that raises the scientists interest (Okely, Trost, Steele, Cliff, \& Mickle, 2009), when posture is formed during the pre-school period and taking into account fine motor skills peculiarities, it is possible to ensure the optimal movement function (Rodger \& Vishram, 2010). The purpose of this study was to identify the need for animated play programs and risk factors for the development of about 4-7-year-old children's abnormal posture.

Methods. We analysed annual preventive health collaborating with public health professionals and pre-school medical personnel. Two social surveys were conducted using an anonymous online questionnaire for respondents. The first survey included questions to parents/caregivers (interpersonal level) in order to establish the psychomotor development of children up to one year of age and possible causes of abnormal posture formation. The second survey had questions to the kindergarten educators and administration (organizational level) in order to find out the need for animated play programs in the educational process. The survey questions were based on the child's motor development principles. Research participants were 311 parents/caregivers and 117 kindergarten educators. Anonymous online surveys were conducted between October and December of 2018.

Results. According to the analysis of annual preventive health indicators, less than half of the pre-school age children were healthy in Kaunas city and with the age the number of healthy children decreased. Analysis of preventive health checks in pre-school children showed that skeletal muscle disorders were most common in children aged 4 to 6 years. Parents/caregivers, kindergarten educators and the administration indicated that physical activity had a positive effect on the child's posture in the educational institution, but parents/caregivers had doubts that kindergarten had a favourable environment for the child's posture correction.

Conclusion. As a result, most kindergarten educators and administrators as well as parents/caregivers believed that animated play programs in kindergarten would help to improve posture.
\end{abstract}

Keywords: preschool child, physical activity, posture, animated play program.

\section{INTRODUCTION}

I

$\mathrm{n}$ preschool age, intensive biological maturation takes place in children's brain and it determines the dispersion of the child's natural powers, physical, cognitive, emotional, social development, and have influence on the success at school and further life (Visagurskienè \& Grigonienè, 2016). Good motor skills affect the physical, social and psychological development of children, but this connection is yet not well understood. Pre-school age is crucial for the development of motor skills, as they improve not only through the movement, but also through sensory perception, which integrates into complex and interconnected forms, strongly evolving language that controls human actions (Visagurskienè \& Grigonienè, 2016). Good motor skills have been shown to have a positive effect on the cardiovascular system (Lubans, Morgan, Cliff, Barnett, \& Okely, 2010), body weight (Lubans 
et al., 2010; Morano, Colella, \& Caroli, 2013) and overall body condition (Viholainen et al., 2014). The Danish preschool educational institutions pay special attention to the development of motor skills - creating and implementing programs, and projects that integrate ten thousand children (Hestbaek et al., 2017).

Inactivity negatively affects the musculoskeletal system: it decreases muscle strength, static and dynamic endurance, and tone. Insufficient back muscle tone of 6-7-year-old children does not guarantee stable spin curves (Davison \& Jago, 2009). The preschool children's posture is an important society problem that raises the scientists interest (Okely et al., 2009), when posture is formed during pre-school period and, taking into account the peculiarities of fine motor skills, it is possible to ensure the optimal movement function (Rodger \& Vishram, 2010). Carrying out the annual preventive children's health checks (order No. 301 of the Minister of Health of the Republic of Lithuania of 31 May 2000), the proportion of absolutely healthy children was 35.5 percent of prophylactically examined children in the school year 2017/2018. The data showed that with children's age the health proportion decreased. One of the major children health problems are skeletal muscle disorders, which were found in $15.1 \%$ of the prophylactically examined children. It is known that during the corrected exercises (physiotherapy) the whole movement system improves when the neck, shoulders, abdomen, back and hips are strengthened, also it improves speed, strength, endurance, mobility, the muscles engaged into the work, metabolic circulation and reduces pain (Macanovic \& Momčinovic-Gajic, 2010). Bendixen and Kreider (2011) showed that using gaming interventions, fine motor skills and vision-related motor skills clearly improved.

Games are a normal process in pre-school age children that gives them joy and relaxation, giving the opportunities to develop their cognitive abilities, allowing to express emotions, develop fantasy and creativity. While playing a child learns about himself/herself, others and the world, learns, how to filter the information. Pre-school children spend few hours playing on a computer (Davison et al., 2011), usually using mobile phones with certain online platforms. However, the hypokinesia should not be forgotten as a negative effect on musculoskeletal system, and the lack of hypokinesia does not guarantee 6-7-year-old children's stable spin curves (Wojna, Anwajler, Hawrylak, \& Barczyk,
2010). According to research, children should use a targeted physiotherapy program as a preventive measure to avoid postural and fine motor skill disorders (Dobbins, Corby, Robeson, Husson, \& Tirilis, 2009). Therefore, animated play programs could be one way to help solve posture problems. Of course, it includes a multitude of challenges and virtual worlds of imagination. Therefore, a thoughtful and creative applicable design program should be created to draw the player in the proposed activities. Animated play programs, where playerschildren create stories with beloved fairy tales or cartoon characters, create songs through playing activity and imagination, will motivate them to engage in a targeted physiotherapy program more as a preventive measure to avoid posture and fine motor skill disorders. Nowadays, there are no Lithuanian language animated play programs that thoughtful and creative game design gaming programs would perfectly involve the player into the proposed activities.

This research is motivated by the need to explore some of the challenges and related opportunities at the intersection of the appearing skeletal muscle disorders and physical activity related behavior modification challenges in children, and the growing role of gamification and learnification on innovative technologies in recent years in the lives of these pediatric digital natives. While there is some early evidence of the positive impact of video games on fine motor skills in children (Bendixen \& Kreider, 2011), the mechanisms underlying these improved outcomes are yet to be understood. Hence, it is important to identify the possible factors to physical activity. It is known that parental education is one of contributing factors in children's physical activity (Santos, Esculcas, \& Mota, 2004), also kindergarten educators play an important role to physical activity in children life (Ball, Cleland, Timperio, Salmon, \& Crawford, 2009).

Thus, the purpose of this study was to identify the need for animated play programs and risk factors for the development of 4-7-year-old children's abnormal posture. Objectives:

1. To evaluate the demand of animated play programs according to the annual preventive child health examinations data of preschool aged children.

2. To determine the need of animated play programs at interpersonal (parents/caregivers) and organizational (kindergarten educators and administration) levels. 


\section{METHODS}

Organization of research. We performed the analysis of annual preventive health indicators (order No. 301 of the Minister of Health of the Republic of Lithuania of 31 May 2000) using data from no. 0.271/an examination form in collaboration with public health specialists and preschool medicine staff. This form of examination (No. 0.27-1/a) showed child's health status: blood pressure, hearing, sight, bone and muscle, respiratory and nervous system disorders. There is also a conclusion about the physical fitness of the pupil - child to be attributed to one of three physical education groups. Data of children development disorders and sickness rates are provided by Kaunas City Municipality's Public Health Bureau, which performs one of its functions - public health monitoring. The sickness rates analysis of pre-school age children is based on the examination form no. 0.27-1/a. data, which is provided by public health specialists.

The need for animated play programs at interpersonal (parents/caregivers) and organizational (kindergarten educators and administration) levels. Two social surveys were conducted using an anonymous electronic questionnaire for respondents. The first survey presents questions to parents/caregivers (interpersonal level) in order to find out the psychomotor development of children up to one year of age and possible causes of abnormal posture formation and the need for animated play programs in the educational process. The second survey presents questions to the kindergarten educators and administration (organizational level) in order to find out the need for animated play programs in the educational process. The surveys were based on the child's motoric development principles. The interpersonal level assessment survey consisted of 20 questions about child's abnormal posture, physical activity in the kindergarten, preventive measures, and the need for animated play program in the educational institution. The organizational level assessment survey consisted of 12 questions about providing assistance to children with position and motion disorders, physical activity in kindergartens, employee competences, preventive measures and the need of a play program in the educational institution.

As many as 311 parents/caregivers aged 3140 years (6 percent up to 25 years old, 19 percent 25-30 years old, 9 percent more than 41 years old), participated in the survey together with 117 kindergarten educators and administrators.

Anonymous online surveys were conducted between October and December of 2018. The subjects were randomly selected. Before completing the survey, in the first survey page the purpose of the study was explained for subjects, it also explained the possible uncertainties. Completing the survey took 12 minutes on average. The data were processed and analysed using the statistical package SPSS 13.0. To test the hypothesis, a chisquare test $\left(\chi^{2}\right)$ was applied, and a statistical conclusion reliability level was $p<.05$.

\section{RESULTS}

Analysis of annual preventive health indicators. The 13306 preschool children attended educational institutions at 2018/2019 school year in Kaunas City Municipality. Preventive health was checked in 13209 pre-school children. The proportion of fully healthy students was 35.4 percent of prophylactically tested children. With the children's age the proportion of completely healthy children decreased (Figure 1).

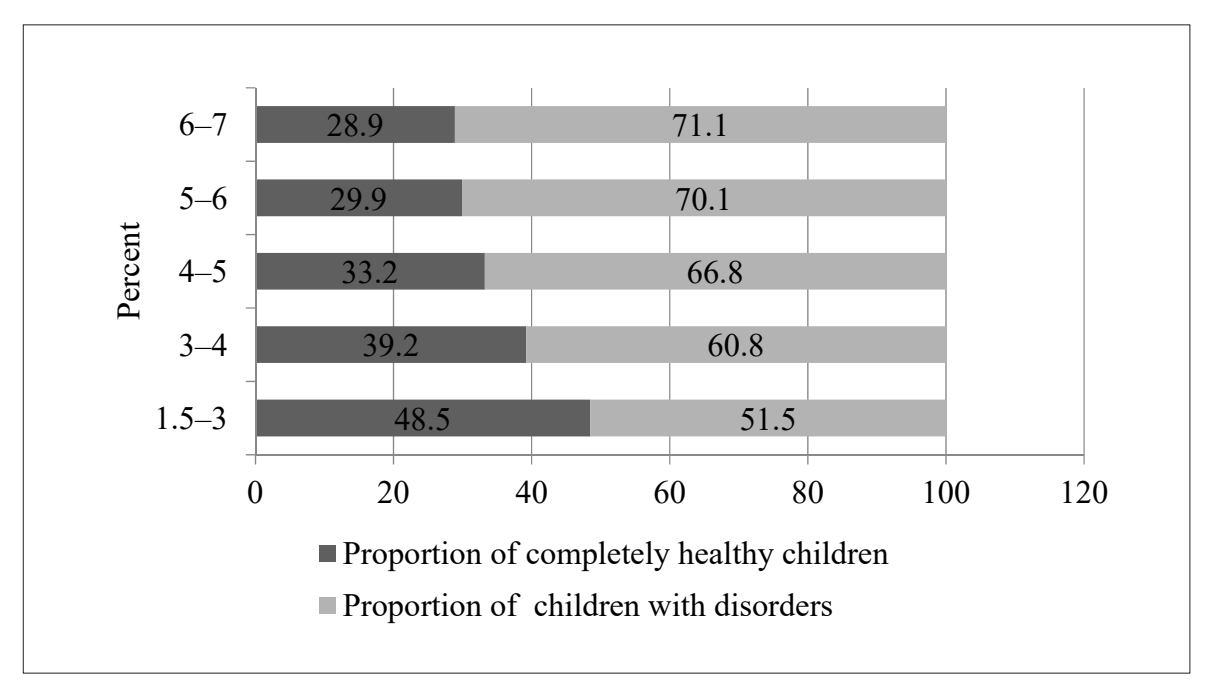

Figure 1. Percentage of completely healthy children by age 
During preventive health checks, the Body Mass Index (BMI) was evaluated for 10799 -preschool children. Normal BMI was found in $96.30 \%$ of children. The $2.40 \%$ of pre-school children had too low body weight, $1.10 \%$ were overweight and $0.2 \%$ had obesity (Figure 2 ).

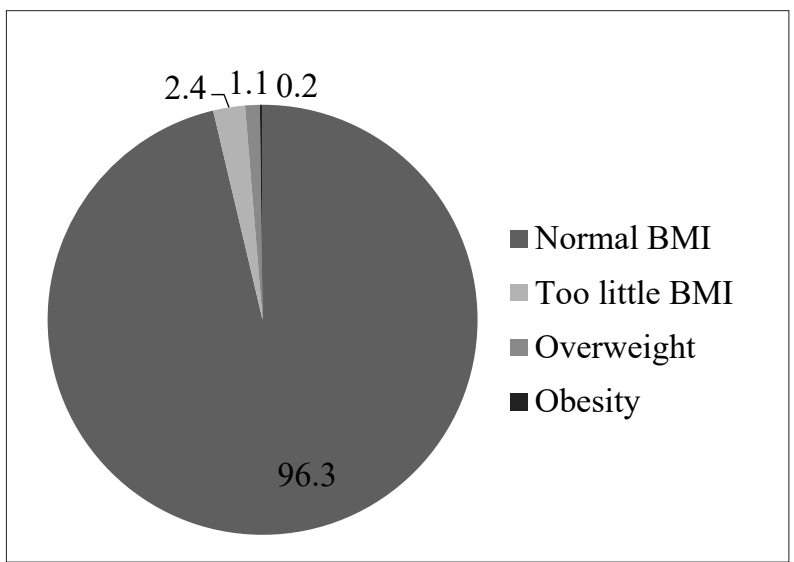

Figure 2. Distribution of body weight index for children with body mass index $(\%)$

The analysis of preventive health checks for preschool children showed that the main disorders were visual, skeletal-muscle disorders and language defects. Musculoskeletal disorders were detected in $16.40 \%$ of children. The types of children's musculoskeletal disorders were found as scoliosis (1.80\% of children) and posture disorders $(15.90 \%$ of children). Musculoskeletal disorders are usually found in children aged 4 to 6 years (Figure 3).

The need for animated play programs at interpersonal (parents/caregivers) and organizational (kindergarten educators and administration) levels. The results showed that parents/caregivers $(66 \%)$ indicated that their children had no posture problems, $20 \%$ had posture problems, $14 \%$ did not know. The majority of parents/caregivers $(88 \%)$ believed that physical activity had a positive effect on children's posture. More than half of the parents/caregivers $(52 \%)$ believed that children did not get enough information about irregular posture, $33 \%$ of parents/caregivers did not know and $15 \%$ of parents/caregivers believed that children received enough information about irregular posture in the kindergarten. More than half of the interviewed parents/caregivers (54\%) did not know or doubted that the kindergarten had a favourable environment for the posture correction, $24 \%$ agreed that this educational institution had a favourable environment and 13\% thought that that a kindergarten had favourable environment for children's posture correction (Table 1). Parents/caregivers made suggestions to improve irregular posture: "Explanations for children, visual

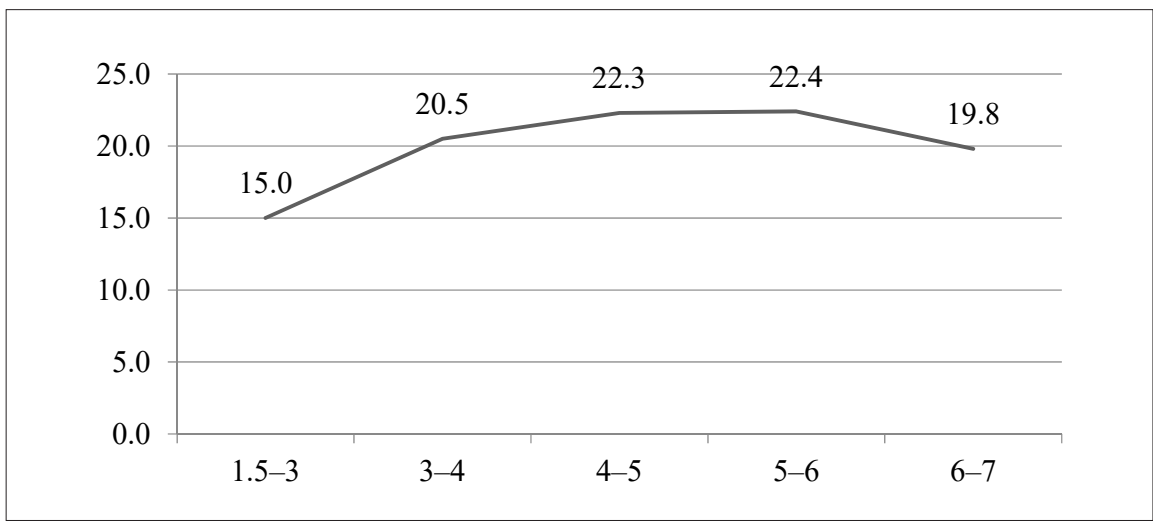

Figure 3. Distribution of musculoskeletal disorders by age $(\%)$

\begin{tabular}{|c|c|c|c|c|}
\hline Statements & Yes & No & \multicolumn{2}{|c|}{ Don't know } \\
\hline Does your child have posture problems? & 20 & 66 & \multicolumn{2}{|l|}{14} \\
\hline $\begin{array}{l}\text { In your opinion, do physical activities in the } \\
\text { educational institution have a positive effect on } \\
\text { the child's posture? }\end{array}$ & 88 & 6 & \multicolumn{2}{|l|}{6} \\
\hline $\begin{array}{l}\text { Do you think that children get enough informa- } \\
\text { tion about irregular posture? }\end{array}$ & 15 & 52 & \multicolumn{2}{|l|}{33} \\
\hline \multirow{2}{*}{$\begin{array}{l}\text { Do you think the kindergarten has a favourable } \\
\text { environment for posture correction? }\end{array}$} & Yes & Don't know & \multicolumn{2}{|c|}{ Partly } \\
\hline & 24 & 54 & \multicolumn{2}{|l|}{13} \\
\hline \multirow{2}{*}{$\begin{array}{l}\text { Do you think animated exercise in kindergarten } \\
\text { would improve posture and flat feet activities? }\end{array}$} & Yes & No & Don’t know & Partly \\
\hline & 77 & 1 & 9 & $13 \%$ \\
\hline
\end{tabular}

Table 1. Percentage distribution of parents/caregivers identifying possible causes of irregular posture 
information", "It would be good if the physical activity lessons, as well as the children sitting (when eating, drawing, and playing), emphasize standing, sitting and overall posture", "Exercises are needed".

Kindergarten educators and administration $(76 \%)$ indicated that their institution provided qualified help for children with positioning and movement disorders. Almost all kindergarten educators and administrations (97\%) pointed out that they paid attention to the children's irregular posture during the education process. More than a half of kindergarten educators and administrations $(65 \%)$ indicated that when they notice children' irregular posture, they always correct it, sometimes (34\%) of kindergarten educators and administrations admitted making the corrections. The kindergarten educators and the administration indicated that special exercises (corrective-physiotherapy) for posture corrections $(46 \%)$ were carried out in their institution during physical activity, but $54 \%$ of the respondents observed that there were no special exercises (corrective-physiotherapy) for posture corrections. Only 17\% of kindergarten educators and administrations indicated that they had enough knowledge and skills to work with children positioning and movement disorders, 37\% of respondents noticed that they had not enough knowledge and skills and $46 \%$ of respondents noticed that they doubted about their knowledge and skills. Most of the kindergarten educators and administrators (54\%) thought that animated exercise in kindergarten would help to improve irregular posture, $27 \%$ of kindergarten educators and administrations partially thought so, and $17 \%$ of the kindergarten educators and administrations had no opinion on this issue (Table 2).

The correlation calculation results between parents/caregivers and kindergarten educators/ administration that animated exercise in kindergarten would help to improve irregular posture showed strong links (.830). The correlation calculation results between parents/caregivers that physical activities in the educational institution had a positive effect on the child's posture and kindergarten educators/administration that the support was qualified for children with positioning and movement disorders would help to improve irregular posture showed average links (.630). The correlation calculation results between parents/ caregivers that children got enough information about irregular posture in kindergarten and kindergarten educators/administration that they paid attention to the children's irregular posture during educational process showed average links (.560). The correlation calculation results between parents/caregivers that children got enough information about irregular posture in kindergarten and kindergarten educators/administration that they always corrected the children's irregular posture during educational process showed average links (.530). The correlation calculation results between parents/caregivers that the kindergarten had a favourable environment for posture correction and kindergarten educators/administration that there were special exercises (corrective-physiotherapy) for posture corrections in the kindergarten showed average links (.560). The correlation calculation results between parents/caregivers that the

Table 2. Percentage distribution of educators and administration identifying the need for play programs in the educational process

\begin{tabular}{|c|c|c|c|c|}
\hline Statements & Yes $(\%)$ & \multicolumn{3}{|c|}{ No $(\%)$} \\
\hline $\begin{array}{l}\text { Is the support qualified for children with positioning and } \\
\text { movement disorders? }\end{array}$ & 76 & \multicolumn{3}{|c|}{24} \\
\hline $\begin{array}{l}\text { Do you pay attention to the children's irregular posture } \\
\text { during educational process? }\end{array}$ & 97 & \multicolumn{3}{|c|}{13} \\
\hline $\begin{array}{l}\text { Are there special exercises (corrective-physiotherapy) } \\
\text { for posture corrections in the kindergarten? }\end{array}$ & 46 & \multicolumn{3}{|c|}{54} \\
\hline \multirow{2}{*}{ Do you always correct the children's irregular posture? } & Yes & No & \multicolumn{2}{|c|}{ Sometimes } \\
\hline & 65 & 1 & \multicolumn{2}{|c|}{34} \\
\hline \multirow{2}{*}{$\begin{array}{l}\text { Do you have the knowledge and skills to work with } \\
\text { children with positioning and movement disorders? }\end{array}$} & Yes & No & \multicolumn{2}{|c|}{ Doubt } \\
\hline & 17 & 37 & \multicolumn{2}{|c|}{46} \\
\hline \multirow{2}{*}{$\begin{array}{l}\text { Do you think animated exercise in kindergarten would } \\
\text { help to improve irregular posture? }\end{array}$} & Yes & No & Don't know & Partly \\
\hline & 54 & 1 & 17 & 27 \\
\hline
\end{tabular}


kindergarten had a favourable environment for posture correction and kindergarten educators/ administration that they had the knowledge and skills to work with children with positioning and movement disorders showed average links (.540).

\section{DISCUSSION}

According to the analysis of annual preventive health indicators, the number of healthy preschool children was $35.4 \%$ of prophylactically tested children in Kaunas city. The proportion of completely healthy children decreases with the age. An analysis of preventive health checks for preschool children have shown that the main disorders of children are visual, skeletal-muscle disorders and language defects. Musculoskeletal disorders were detected in $16.4 \%$ of prophylactically tested children. Musculoskeletal disorders were usually found in children aged 4 to 6 years. Also parents/caregivers $(66 \%)$ have reported that skeletal muscle disorders are quite common in their children's life. Good motor skills are considered important for children's physical, social, and psychological development (Gallahue \&Ozmun, 2002) and may even be the foundation for an active lifestyle, since several studies have shown a positive association between good motor skills and higher levels of physical activity (Lubans et al., 2010). Consequently, there is evidence of many health benefits to be gained from an improvement in motor skills. For instance, it has been demonstrated that good motor skills positively influence cardiorespiratory fitness (Lubans et al., 2010) and body weight (Morano at al., 2011) as well as sports participation (Krombholz, 2010), all suggesting that early competency in motor skills may have important health implications. Furthermore, there are indications of relationships with language development (Vukovic et al., 2010), executive function (Diamond \& Lee, 2011), and general wellbeing (Viholainen et al., 2006). However, most of the existing studies on motor performance are either cross-sectional, and therefore do not provide evidence of a potential causal relationship, or they include only short-term follow-up. The majority of parents/caregivers (88\%) have believed that physical activity has a positive effect on the child's posture in the educational institution, but parents/caregivers $(54 \%)$ had doubt that kindergarten had a favourable environment for the child's posture correction. Parents/caregivers (52\%) indicated that children did not get enough information about correct posture. Therefore, toddler and preschool age appears to be a particularly important period for the development of motor skills. Early childhood is also the age where practicing fundamental movement skills is necessary to create a foundation for more complex movement activities of daily living, recreation, and sports in later childhood (Gallahue \& Ozmun, 2002). In Denmark, $92 \%$ of all 3-5-yearold children spend a high proportion of their waking hours at preschool (Lindelof, Nielsen, \& Pedersen, 2013). Consequently, this arena provides an ideal opportunity for all children, despite socioeconomic background, to develop and improve their motor skills.

Kindergarten educators and administrators (76\%) believe that their institution provides qualified assistance to children with positioning and movement disorders. Almost all kindergarten educators and administrations have pointed out that they pay attention ( $97 \%$ of respondents) to the child's irregular posture during the education process. Most of the kindergarten educators and administrators (54\%), parents/caregivers (77\%) have thought that animated play programs in kindergarten would improve posture and flat footing. Games have been shown to have positive impact on children (Serrone, 2012). Many children spend several hours a day playing video games (Roberts, Foehr, \& Rideout, 2005), mostly on mobile devices, a platform through which they can learn about health in a fun and enjoyable way. This may be one approach to address the multi-faceted challenge of the paediatrics.

\section{CONCLUSION}

According to the analysis of annual preventive health indicators, less than half of the pre-school age children are healthy in Kaunas city and with the age the number of healthy children decreases. An analysis of preventive health checks in pre-school children has shown that skeletal muscle disorders are most common in children aged 4 to 6 years. Parents/caregivers, kindergarten educators and the administration have indicated that physical activity has a positive effect on the child's posture in the educational institution, but parents/caregivers have doubt that kindergarten has a favourable environment for the child's posture correction. As a result, most kindergarten educators and administrators and parents/caregivers have believed that animated play programs in kindergarten would help to improve posture. 


\section{REFERENCES}

Ball, K., Cleland, V. J., Timperio, A. F., Salmon, J., \& Crawford, D. A. (2009). Socioeconomic position and children's physical activity and sedentary behaviors: Longitudinal findings from the CLAN study. Journal of Physical Activity and Health, 6, 289-298. https://doi. org/10.1123/jpah.6.3.289

Bendixen, R. M., \& Kreider, C. M. (2011). Centennial vision-review of occupational therapy in the practice area of children and youth. The American Journal of Occupational Therapy, 65, 351-359.

Davison, K., \& Jago, R. (2009). Change in parent and peer support across ages 9 to 15 years and adolescent girls' physical activity. Medicine and Science in Sports Exercise, 41, 1816-1825. doi: 10.1249/ MSS.0b013e3181a278e 2

Diamond, A., \& Lee, K. (2011). Interventions shown to aid executive function development in children 4 to 12 years old. Science, 333(6045), 959-964. https://dx.doi. org/10.1126\%2Fscience. 1204529

Dobbins, M., Corby K. C., Robeson, P., Husson, H., \& Tirilis, D. (2009). School-based physical activity programs for promoting physical activity and fitness in children and adolescents aged 6-18. Cochrane Database System Review, 1(1), Cd007651.

Gallahue, D. L., \& Ozmun, J. C. (2002). Motor Development: A theoretical model. Understanding motor development: Infants, children, adolescents, adults. 5th ed. New York: McGraw-Hill.

Krombholz, H. (2006). Physical performance in relation to age, sex, birth order, social class, and sports activities of preschool children. Perceptual Motor Skills, 102(2), 477-484. doi: 10.2466/PMS.102.2.477-484

Lindelof, A., Nielsen, C. V., \& Pedersen, B. D. (2013). A qualitative, longitudinal study exploring obese adolescents' attitudes towards physical activity. Journal of Physical Activity and Health, 10, 113-21. doi: 10.1123/jpah.10.1.115

Hestbaek, L., Andersen, S.T., Skovgaard, T., Olesen, L. G., Elmose, M., Bleses, D., ... Lauridsen, H. H. (2017). Influence of motor skills training on children's development evaluated in the motor skills in PreSchool (MiPS) study-DK: Study protocol for a randomized controlled trial, nested in a cohort study. Trials, 18, 400.

Lubans, D. R., Morgan, P. J., Cliff, D. P., Barnett, L. M., \& Okely, A. D. (2010). Fundamental movement skills in children and adolescents: Review of associated health benefits. Sports Medicine, 40(12), 1019-1035. https:// doi.org/10.2165/11536850-000000000-00000

Macanovic, N., \& Momčinovic-Gajic, A. (2010). Corrective gymnastics function in trouble postural disorders. Sport Expert, 3(2), 5-16.
Morano, M., Colella, D., \& Caroli, M. (2011). Gross motor skill performance in a sample of overweight and non-overweight preschool children. International Journal Pediatric Obesity, 6 (Suppl.), 2, 42-46. https:// doi.org/10.3109/17477166.2011.613665

Okely, A. D., Trost, S. G., Steele, J. R., Cliff, D. P., \& Mickle, K. (2009). Adherence to physical activity and electronic media guidelines in Australian pre-school children. Journal of Pediatrics and Child Health, 45, 5-8. https://doi.org/10.1111/j.1440-1754.2008.01445.x

Roberts, D., Foehr, U., \& Rideout, V. (2005). Generation M: Media in the lives of 8-18 year olds. Kaiser Family Foundation Study, 12.

Rodger S., Vishram, A. (2010). Mastering social and organization goals: Strategy use by two children with Asperger syndrome during cognitive orientation to daily occupational performance. Physical and Occupational Therapy in Pediatrics, 30, 264. doi: 10.3109/01942638.2010.500893.

Santos, M. P., Esculcas, C., \& Mota, J. (2004). The relationship between socioeconomic status and adolescents' organized and non-organized physical activities. Pediatric Exercise Science, 16, 210-218.

Serrone, C. (2012). Mood management and video-game engagement: The importance of user-experience and gender in assessing the psychological effects of videogame play. Master's Theses. Paper 4211. San Jose State University.

Viholainen, H., Ahonen, T., Lyytinen, P., Cantell, M., Tolvanen, A., \& Lyytinen, H. (2006). Early motor development and later language and reading skills in children at risk of familial dyslexia. Development Medicine and Child Neurology, 48(5), 367-373. https:// doi.org/10.1017/S001216220600079X

Viholainen, H., Aro, T., Purtsi, J., Tolvanen, A., \& Cantell, M. (2014). Adolescents' school related selfconcept mediates motor skills and psychosocial wellbeing. British Journal Education Psychology, 84(Pt 2), 268-280. doi: 10.1111/bjep.12023

Visagurskienè, K., \& Grigonienè, J. (2016). Ikimokyklinio ir pradinio mokyklinio amžiaus vaiku fiziniu ypatybiu testavimas ir ugdymas. Kaunas: LSU.

Vukovic, M., Vukovic, I., \& Stojanovik, V. (2010). Investigation of language and motor skills in Serbian speaking children with specific language impairment and in typically developing children. Research in Development Disabilities, 31(6), 1633-1644. doi: 10.1016/j.ridd.2010.04.020

Wojna, D., Anwajler, J., Hawrylak, A., \& Barczyk, K. (2010). Assessment of body posture in younger schoolchildren. Physiotherapy, 18(4), 27-39. http:// dx.doi.org/10.2478/v10109-010-0079-7 